REVIEW ARTICLE

\author{
A.S. Vagal \\ J.L. Leach \\ M. Fernandez-Ulloa \\ M. Zuccarello
}

\title{
The Acetazolamide Challenge: Techniques and Applications in the Evaluation of Chronic Cerebral Ischemia
}

\begin{abstract}
SUMmARY: The acetazolamide (ACZ) challenge test is a useful clinical tool and a reliable predictor of critically reduced perfusion. In patients with chronic steno-occlusive disease, the ability to maintain normal cerebral blood flow by reducing vascular resistance secondary to autoregulatory vasodilation is compromised. Identification of the presence and degree of autoregulatory vasodilation (reflecting the cerebrovascular reserve) is a significant prognostic factor in patients with chronic cerebrovascular disease. The pharmacologic challenge of a vasodilatory stimulus such as ACZ can also be used to optimize the treatment strategies for these patients. The pathophysiology, methods, and clinical applications of the ACZ challenge test are discussed in this article.
\end{abstract}

V iability of the cerebral parenchyma is dependent on the ability of the brain vasculature to provide adequate levels of cerebral blood flow (CBF). In patients with chronic stenoocclusive disease, the ability to maintain normal CBF by reducing vascular resistance is compromised. Identification of the degree of autoregulatory vasodilation reflects cerebrovascular reserve (CVR), which is a significant prognostic factor in chronic cerebrovascular disease. ${ }^{1-5}$ Flow reserve can be assessed with the use of paired blood flow measurements, with the initial measurement obtained at baseline and the second, after a vasodilatory stimulus, such as acetazolamide (ACZ). ${ }^{6}$

\section{Pathophysiology of Chronic Cerebrovascular Disease}

Chronic cerebral hypoperfusion is usually the result of occlusion or stenosis of large arteries in the neck or the circle of Willis. Clinical symptoms and manifestations of brain ischemia in patients with chronic cerebrovascular disease (CVD) develop as a consequence of 2 main mechanisms: embolic events from atherosclerotic plaques resulting in local compromise of blood flow and systemic hemodynamic alterations that further reduce an already compromised cerebral perfusion state. ${ }^{7}$

The hemodynamic changes due to a decline in cerebral perfusion pressure have been studied by many investigators. ${ }^{6,8-11}$ Chronic CBF restriction causes a progressive decrease in cerebral perfusion pressure (CPP). Initially, decreases of CPP cause varying degrees of autoregulatory vasodilation of small distal arterioles. ${ }^{12}$ Powers ${ }^{10}$ and Powers et $\mathrm{al}^{11}$ proposed a 2-stage classification of hemodynamic impairment in patients with CVD. In stage I (autoregulatory vasodilation), autoregulation reduces cerebral vascular resistance. $\mathrm{CBF}$ and oxygen extraction fraction (OEF) are not

Received January 4, 2009; accepted January 5

From the Departments of Radiology (A.S.V., J.L.L., M.F.-U.) and Neurosurgery (M.Z.), University of Cincinnati College of Medicine, Cincinnati, Ohio; Department of Radiology (J.L.L.), Cincinnati Children's Hospital Medical Center; and The Neuroscience Institute (A.S.V., J.L.L., M.Z.), Cincinnati, Ohio.

Please address correspondence to Achala S. Vagal, MD, Department of Radiology, Section of Neuroradiology, University of Cincinnati College of Medicine, 234 Goodman St, Cincinnati, OH 45267-0762; e-mail: vagala@healthall.com

Indicates open access to non-subscribers at www.ajnr.org

DOI 10.3174/ajnr.A1538 significantly changed. Increases of cerebral blood volume $(\mathrm{CBV})$ and mean transit time $(\mathrm{MTT})$ are 2 parameters that reflect this initial phase of compensatory autoregulatory vasodilation. Further decreases of CPP beyond cerebral autoregulatory vasodilation capacity eventually result in stage II (autoregulatory failure), characterized by decreases of $\mathrm{CBF}$ and increases of OEF. When the CBF decreases, neurons increase the fraction of oxygen extracted from the blood to maintain normal neurologic function. ${ }^{13}$ This phenomenon of reduced $\mathrm{CBF}$ and increased $\mathrm{OEF}$ has been termed "misery perfusion."11,14

Derdeyn et $\mathrm{al}^{9}$ have more recently shown that autoregulatory vasodilation and increased oxygen extraction occur simultaneously. Slight reductions in CBF through the autoregulatory range lead to slight but measurable increases in $\mathrm{OEF}^{15}$ When autoregulatory capacity is finally exceeded, CBF decreases more rapidly and OEF increases dramatically. ${ }^{16}$ The CBV is more variable in the autoregulatory range. ${ }^{9}$ The cerebral rate for oxygen metabolism $\left(\mathrm{CMRO}_{2}\right)$ remains unchanged over the initial and late decreased levels of CPP. ${ }^{9,17}$ As the CPP falls further, oxygen extraction reaches a maximum. Further decreases in CPP will result in an inability to maintain adequate blood flow and lead to varying degrees of brain ischemia.

Evaluation of these compensatory mechanisms is important in patients with CVD to determine the risk of future ischemic events and in the selection and planning of therapeutic interventions. Generally speaking, 3 approaches can be used in the evaluation of patients with $\mathrm{CVD}^{6}$ : One requires the measurement of the $\mathrm{CBV} / \mathrm{CBF}$ ratio, mathematically equivalent to the MTT. The second approach (and the focus of this article) attempts to determine the degree of cerebral flow reserve. This is accomplished by comparing CBF under baseline conditions and after a vasodilatory stimulus such as ACZ. Finally, direct measurements of OEF to identify patients with increased oxygen extraction (currently performed by using positron-emission tomography $[\mathrm{PET}]$ ) can be performed.

\section{Cerebrovascular Reactivity}

Alterations in blood flow secondary to a vasodilatory stimulus (such as ACZ) can be used to estimate CVR, which is calculated as the percentage increase in $\mathrm{CBF}$ after $\mathrm{ACZ}$ relative to baseline $e^{1,18}$ : 

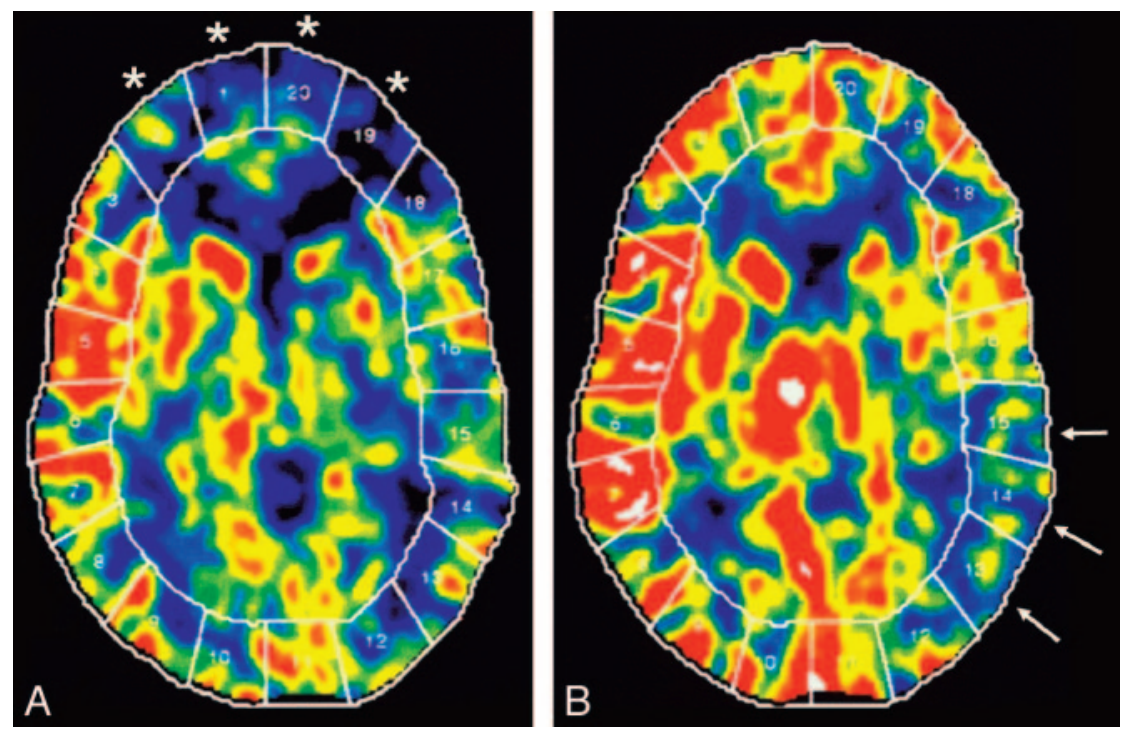

Fig 1. Xe-CT CBF maps in a patient with Moyamoya disease. $A$, Baseline. B, After ACZ administration. Baseline scan $(A)$ shows reduced $\mathrm{CBF}$ in the bilateral $\mathrm{ACA}$ and anterior watershed areas (areas 1, 2, 19, and 20, asterisk). After ACZ, there is a robust increase in the CBF, indicating a normal cerebral reserve in these territories. There is reduced baseline flow with decreased augmentation of CBF after ACZ, indicating poor cerebral reserve in the left posterior MCA and the left posterior watershed territories (areas 13-15, arrows).

$$
\mathrm{CVR}=\frac{\mathrm{CBF}(\text { Post }-\mathrm{ACZ})-\mathrm{CBF}(\text { baseline })}{\mathrm{CBF}(\text { baseline })} \times 100 .
$$

Vascular territories harboring vaso-occlusive disease undergo compensatory vasodilation up to a maximal level. This precludes further dilation of the arterioles in the affected region in response to ACZ; therefore, the expected normal increases of $\mathrm{CBF}$ following ACZ challenge are blunted compared with normal brain parenchyma.

On the basis of studies using stable xenon-enhanced CT (Xe-CT) and ACZ challenge, Rogg et $\mathrm{al}^{19}$ classified 3 types of patient responses to ACZ:

Type I patients have normal baseline CBF that increases after ACZ challenge.

Type II patients have areas of decreased CBF on baseline studies that increase after ACZ administration.

Type III patients have decreased CBF at baseline and a paradoxic continued reduction in regional CBF after ACZ administration.

Type III responses appear to define those patients who are the most likely to benefit from surgical revascularization. ${ }^{19}$ This final category likely relates to a steal phenomenon, indicating a decrease in blood flow in regions that are already maximally dilated, ${ }^{20,21}$ identified with quantitative $\mathrm{CBF}$ measurements. $^{22}$

\section{ACZ}

ACZ is a carbonic anhydrase inhibitor that penetrates the blood-brain barrier slowly and acts as a cerebral vasodilator agent. Inhibition of carbonic anhydrase causes carbonic acidosis, which induces a considerable increase in $\mathrm{CBF} .{ }^{23} \mathrm{ACZ}$ is safe to administer and is generally well tolerated. Systemic blood pressure, heart and respiratory rates, arterial $\mathrm{pH}$, arterial $\mathrm{CO}_{2}$ pressure, and $\mathrm{CMRO}_{2}$ are unaffected. Most common side effects are acute and transient, including transient circumoral numbness, paresthesias, malaise, and headache. ${ }^{23,24} \mathrm{Re}-$ versible pontine ischemia caused by ACZ challenge has been discussed in a case report ${ }^{25}$; however, Piepgras et $\mathrm{al}^{26}$ reported no acute ischemic sequelae in more than 1000 studies with the use of ACZ.

Contraindications to ACZ administration are hypersen- sitivity to other sulfonamides, electrolyte disturbances, marked kidney and liver disease, adrenocortical insufficiency, and long-term use in chronic noncongestive angle-closure glaucoma. $^{27}$

A standard dose of $1000 \mathrm{mg}$ intravenously is used for the ACZ challenge test. Peak CBF augmentation occurs at approximately 10-15 minutes after intravenous bolus administration. A 30\%-60\% increase in CBF is achieved in healthy subjects. ${ }^{28}$ Criteria that have been used to define an abnormal response to $\mathrm{ACZ}$ include $<10 \%$ increase in the absolute $\mathrm{CBF}$ or an absolute change of $<10 \mathrm{~mL} / 100 \mathrm{~g} / \mathrm{min}^{29}$

\section{Imaging Techniques}

There is a large armamentarium of imaging techniques for assessing the adequacy of cerebral perfusion. These include PET, single-photon emission CT (SPECT), Xe-CT, dynamic perfusion CT (PCT), MR imaging dynamic susceptibility contrast, arterial spin-labeling (ASL), and transcranial Doppler sonography.

\section{$\mathrm{Xe}-\mathrm{CT}$}

Xe-CT combined with ACZ challenge is an established technique, which has been used for $>20$ years to evaluate chronic cerebral ischemia. It provides quantitative assessment of CBF and CVR (Fig 1). The inhaled xenon gas dissolves in blood rapidly and freely crosses the blood-brain barrier and concentrates in the brain by virtue of its liposolubility. CBF is calculated by measuring the rate of xenon clearance from the brain by using the Kety-Schmidt model, which provides reliable CBF quantization, along with high-resolution imaging. ${ }^{28,30}$ Because of the short cerebral residence time of inhaled xenon, the study can be repeated in the same session. Xe-CT is an expensive and complex examination, requiring excellent patient cooperation, the presence of an anesthetist, and the use of specialized and expensive equipment. Side effects of xenon inhalation, such as a decrease in respiratory rate, headache, nausea, vomiting, and convulsions may occasionally occur. ${ }^{31}$ In the United States, xenon is not currently approved by the US Food and Drug administration for clinical Xe-CT assessment. 

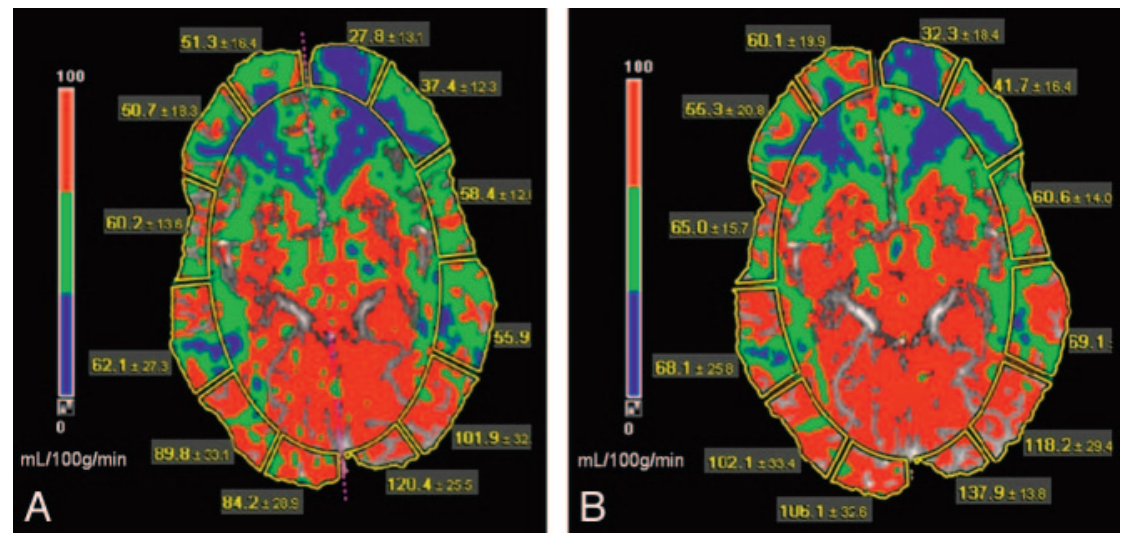

Fig 2. A 34-year-old man with severe headache and blurry vision was diagnosed with Moyamoya disease. CT perfusion maps. A, Baseline. B, After ACZ administration. CBF (measured in $\mathrm{mL} / 100 \mathrm{~g} / \mathrm{min}$ ) is diminished in bilateral $A C A$, ACA-MCA watershed, and the MCA territories (depicted as blue to green). These areas show a very suboptimal increase in CBF after ACZ administration and thus exhibit limited CVR. Note the increased CBF secondary to vasodilatory capacity in the PCA and MCA-PCA distribution after ACZ administration.

\section{PCT}

PCT is a noninvasive method that provides CBF, CBV, and MTT values and can be combined successfully with ACZ to assess cerebral hemodynamics more completely. The feasibility of CTP in the evaluation of chronic ischemia has been encouraging in various studies. ${ }^{32-34}$ Furukawa et a ${ }^{35}$ studied the usefulness of PCT in the evaluation of chronic cerebral ischemia and compared the technique with Xe-CT. In their study, the relative scores of CBF obtained by PCT correlated well with Xe-CT values, though the absolute values did not show as good a correlation. CTP imaging has also been validated against PET. ${ }^{36}$ Bisdas et $\mathrm{al}^{37}$ studied 12 patients with chronic carotid stenosis who underwent dynamic PCT and PET studies. ${ }^{37}$ CBF measurements from PCT correlated well with PET-derived CBF values. This study also reported overestimation of CBF in PCT compared with PET after ACZ challenge. This has also been reported by Kudo et $\mathrm{al}^{38}{ }^{38}$ who hypothesized that inclusion of surface blood vessels and perforating arteries very likely leads to the overestimation by PCT. ${ }^{38}$ Vascular pixel elimination in PCT analysis can minimize this problem. ${ }^{38}$

PCT with ACZ challenge relies on quantitative assessment; therefore, the reproducibility of the perfusion parameters is important. Establishing a uniform and standard postprocessing technique is essential for maintaining good reproducibility (Fig 2). ${ }^{39,40}$ Use of standard head immobilization techniques and adequate patient coaching are important to minimize patient motion. Waaijer et $\mathrm{al}^{41}$ studied PCT images in 20 patients with unilateral symptomatic carotid artery stenosis to assess the reproducibility of quantitative CTP parameters. This study revealed that MTT is the most reproducible parameter for regional measurements of $\mathrm{PCT}$ and that the use of $\mathrm{CBV}$ and CBF ratios results in better reproducibility compared with absolute $\mathrm{CBV}$ and $\mathrm{CBF}$ values for this patient group. ${ }^{41}$

The choice of a reference artery is critical for accurate CBF measurements in CTP, both in acute and chronic ischemia. However, no general consensus has been reached regarding whether the arterial input function (AIF) ipsilateral or contralateral to the side of stenosis is more accurate. ${ }^{37,42}$ Moreover, the choice of the AIF may be more complex in chronic carotid occlusion because collateral formation through the circle of Willis results in delay and dispersion of the contrast bolus. In a recent study comparing PCT with PET in patients with chronic cervical carotid artery occlusion, Kamath et $\mathrm{al}^{43}$ suggested that CBF values obtained by PCT and PET com- pared favorably when processed by using a dedicated AIF for each territory. ${ }^{43}$ In Moyamoya disease, both anterior and middle cerebral arteries (ACA, MCA) may be occluded. In these cases, the basilar artery or the P1 segment of the posterior cerebral artery (PCA) should be selected. ${ }^{44}$

The advantages of PCT are that it is a rapid, noninvasive, and readily available method that provides $\mathrm{CBF}, \mathrm{CBV}$, and MTT values and can be combined successfully with ACZ to assess cerebral hemodynamics fully. Also, anatomic vascular imaging such as CT angiography can be performed at the same time. One current drawback of PCT is restricted spatial coverage. Continually improving CT technology (wider detector arrays and controlled table movements) will very likely overcome this problem. Other inherent disadvantages of PCT include the risks of ionizing radiation and iodinated contrast. Further studies are needed to establish the accuracy, reliability, and reproducibility of PCT-derived quantitative measurements, but the present data regarding CVR assessment are encouraging.

\section{MR Perfusion}

\section{Dynamic Contrast Bolus MR Perfusion}

MR imaging can detect the changes in magnetic susceptibility during passage of a compact bolus injection of contrast and can yield relative and absolute hemodynamic values of brain perfusion. Dynamic susceptibility contrast MR perfusion, similar to CTP, has the advantages of widespread availability, high spatial resolution, and the ability to obtain concomitant anatomic vascular mapping. As an added advantage, there is a more complete coverage of the brain and no ionizing radiation. One of the disadvantages of MR perfusion is the complex relation between the signal intensity and contrast concentration, resulting in difficulties with absolute perfusion parameter calculation. ${ }^{45,46}$

Assessment of CVR with the ACZ challenge has been described with MR perfusion studies. ${ }^{47-51}$ Perfusion MR imaging before and after ACZ administration compares favorably with technetium Tc99m ethyl cysteinate dimmer (Tc99m-ECD) SPECT for the detection of impaired CVR. ${ }^{52}$ Agreement between PET and MR perfusion was moderate for physiologic $\mathrm{CBF}$ values at rest and after the ACZ challenge in healthy humans. ${ }^{53}$ Similar to CTP, the CBF values reported with MR perfusion were overestimated compared with the gold standard of PET. ${ }^{54-56}$ 


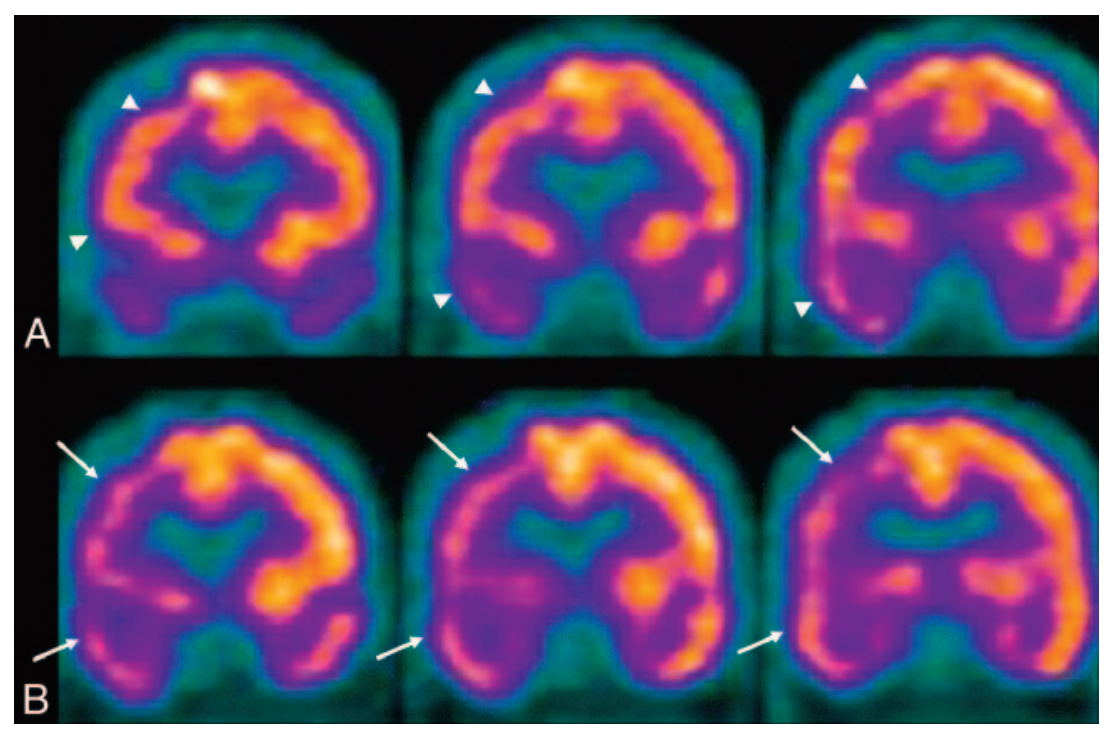

Fig 3. SPECT perfusion study of a 64-year-old man with highgrade right $\mathrm{M} 1$ and $\mathrm{A} 1$ segment stenosis. $A$, Baseline. $B$, After ACZ administration. There is decreased uptake and perfusion (arrows) involving the right frontal, parietal, and temporal lobes on the $A C Z$ study $(B)$, which resolve during baseline conditions (arrowheads).

\section{ASL MR Perfusion}

ASL is a MR perfusion technique that takes advantage of arterial water as a freely diffusible tracer to measure CBF. Because exogenous contrast is not required for this technique, it is completely noninvasive and repeatable. There are only a limited number of studies in humans assessing the feasibility of ASL in chronic ischemia. The combination of ACZ challenge and ASL MR perfusion in CVD produced the expected results of CBF alteration. ${ }^{51}$ Obtaining quantitative accurate CBF data is challenging; however, test-retest reproducibility of these techniques has been encouraging. ${ }^{50}$ A study of a small number of patients with chronic arterial stenosis compared ASL perfusion with ACZ challenge with iodine $123 \mathrm{~N}$-isopropyl-piodoamphetamine ( ${ }^{123}$ I-IMP) SPECT and demonstrated concordant results. ${ }^{57}$ A recent study of a large number of patients with ASL suggested the potential use of this technique for measuring CVR and for serial assessment following revascularization. ${ }^{58,59}$

\section{PET}

Physiologic evaluation of chronic CVD can also be performed with PET, which measures the $\mathrm{CBF}$ and $\mathrm{OEF}$ to estimate cerebral perfusion. It offers the advantage of providing quantitative evaluations useful for the assessment of various parameters of brain metabolism and physiology. PET techniques are not as readily available because the radioisotopes have very short half-lives and need to be produced by cyclotrons, a technology only available in large medical centers or in central commercial radiopharmacies.

Several studies using PET have been conducted to correlate various pathophysiologic aspects of early ischemia with the final outcome of brain tissue at risk for infarction. Patients classified as having hemodynamic ischemia were found in 1 study to have low CBF associated with decreases of $\mathrm{CMRO}_{2}$ on the side of the arterial occlusion. ${ }^{60}$ PET measurement of increased OEF has been shown to be an important and independent predictor of subsequent stroke. ${ }^{61,62}$ Generally speaking, an increased OEF should correspond to decrease in CVR when assessed by challenge tests. These 2 measures, though strongly related, are not equivalent. Recent studies demonstrated that decreases in CVR and increases in OEF did not necessarily parallel each other. ${ }^{63-65}$

PET measurements have been useful in demonstrating reversals of altered OEF because patients improve brain flow through collaterals ${ }^{66}$ and following superficial temporal-toMCA anastomoses. ${ }^{67,14}$ Controlled studies to assess the value of OEF determinations for selection of therapy in patients with carotid occlusive disease are needed to determine the utility of these techniques.

\section{SPECT}

Currently, SPECT is the most readily available nuclear medicine technique for assessment of cerebral hemodynamics and uses radionuclides that concentrate in neurons in direct relation to flow. Technetium Tc99m hexamethylpropyleneamine oxime (HMPAO) and Tc99m-ECD are 2 Technetium Tc99m compounds used in routine clinical practice. There are significant differences in the pharmacokinetics and brain distribution between these 2 agents, but in general, they are equivalent for imaging of the brain. SPECT images with these 2 radionuclides represent the distribution and concentration of the radionuclide within the brain parenchyma according to blood flow and are mainly evaluated qualitatively by visual inspection (Fig 3). Some semiquantitative techniques exist that provide a more objective assessment, especially useful when combined with ACZ challenge. However, currently there are no practical absolute quantitative techniques to measure CBF by using SPECT.

Brain SPECT has also been validated in comparison studies with $\mathrm{O}-15 \mathrm{H}_{2} \mathrm{O}$ PET for evaluation of cerebrovascular reactivity to ACZ challenge in patients with CVD. ${ }^{68,69}$ Several studies have demonstrated the usefulness of brain SPECT in conjunction with ACZ challenge for evaluation of vascular reactivity in patients with various types of vaso-occlusive disease. ${ }^{70-72} \mathrm{Re}$ sponses to ACZ have been studied in patients with Moyamoya disease. ${ }^{73}$ Brain SPECT with Tc99m HMPAO and ACZ challenge was used successfully in the assessment of brain hemodynamics in 15 patients with CVD before and after bypass surgery. ${ }^{74}$

Although evaluation of cerebral hemodynamics in patients 


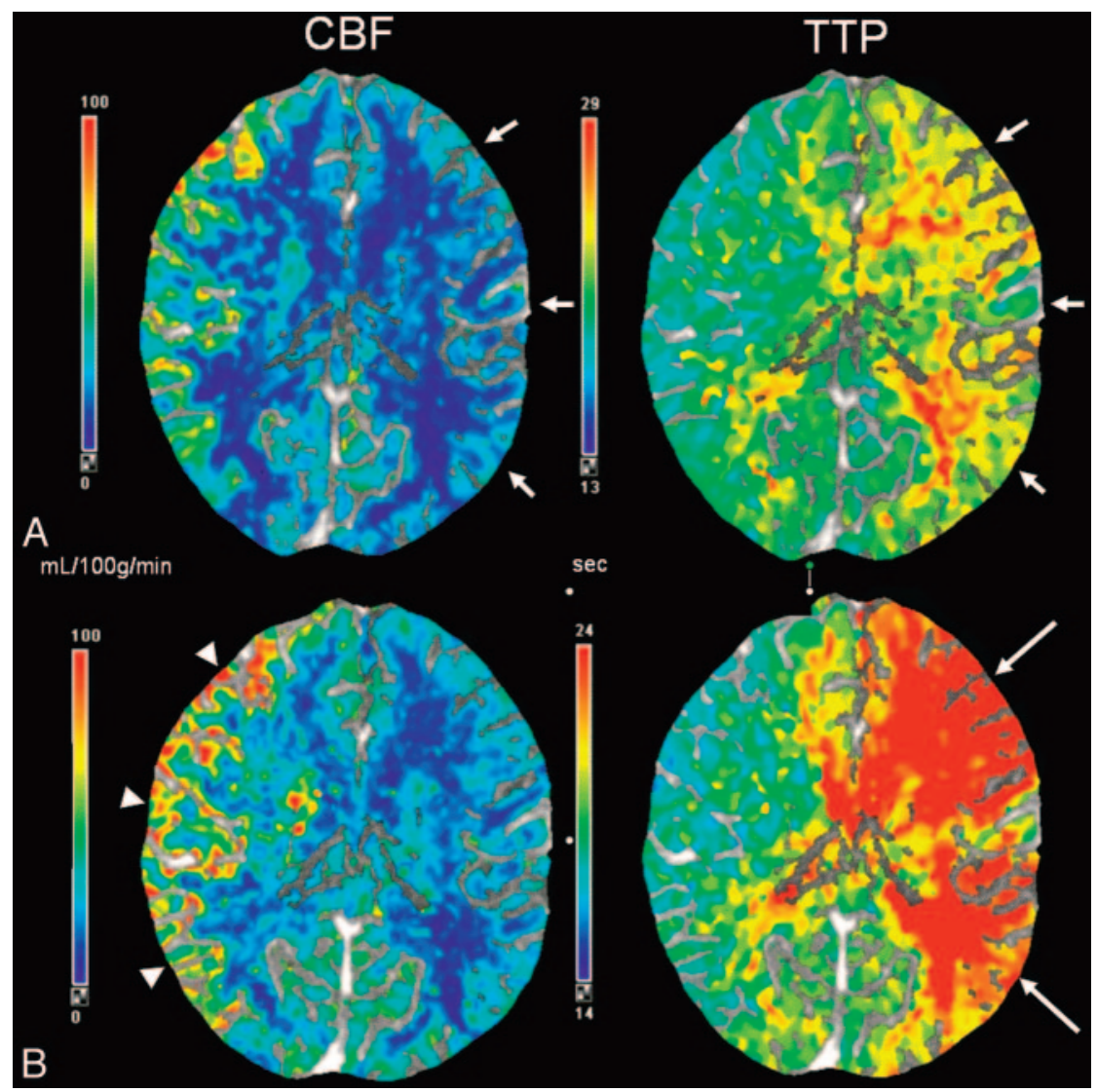

Fig 4. CTP. Chronic left internal carotid artery occlusion. $A$, Baseline. B, After ACZ administration. There is significant hypoperfusion in the left hemisphere at baseline with decreased CBF and increased TTP ( $A$, short arrows). After administration of $A C Z(B), C B F$ decreases throughout the left hemisphere, resulting in negative calculated CVR percentages. The left-sided TTP increases even further in post-ACZ flow maps as seen by the accentuated asymmetry $(B$, long arrows). Note the normal increase in the right-sided CBF after the vasodilatory stimulus of $\mathrm{ACZ}(B$, arrowheads).

with CVD is best performed by using PET, SPECT imaging with ACZ challenge offers a more practical alternative for many centers.

\section{Clinical Applications of the ACZ Challenge}

\section{Stroke Risk Assessment}

Identification of compromise in CVR capacity is important in the evaluation of ischemic stroke. The degree of vascular occlusion in this situation is an incomplete indicator of future stroke risk. ${ }^{75}$ There may be a synergistic effect between embolic phenomenon from atherosclerotic plaque and impaired hemodynamics causing ischemic stroke in large artery atherosclerotic occlusions. ${ }^{76,77}$ Compromised CVR is a key determinant of ischemic infarction, regardless of whether it is precipitated by embolic or hemodynamic factors. ${ }^{75}$

Kuroda et $\mathrm{al}^{2}$ describe a prospectively studied longitudinal cohort of 77 patients in which patients with decreased CBF and CVR resulting from internal carotid artery (ICA) or MCA occlusion had a higher risk of new ischemic stroke than those without. This was one of the first prospective studies to confirm the value of CVR as a predictor of the future stroke risk. ${ }^{2}$ Another prospective study demonstrated that decreased cerebrovascular reactivity to ACZ (determined quantitatively by ${ }^{133} \mathrm{Xe}$ SPECT) is an independent predictor of the 5-year risk of subsequent stroke in patients with symptomatic major cerebral artery occlusion. ${ }^{5}$ Multiple studies of patients with carotid occlusive disease have consistently shown a higher incidence of ischemic complications in those patients with compromised vascular reserve (Fig 4). 3,4,62,78

ACZ-defined CVR can also be used as an additional assess- ment tool in asymptomatic carotid artery stenosis. ${ }^{7,79}$ In a prospective study of 94 patients with asymptomatic carotid artery stenosis of $>70 \%$, Silvestrini et $\mathrm{al}^{79}$ suggested a link between impaired cerebrovascular reactivity and the risk of ischemic events ipsilateral to severe asymptomatic carotid stenosis.

The risk of perioperative cerebral infarction during carotid and cardiac surgery can be estimated by using CVR. Schoof et al ${ }^{80}$ prospectively studied 2797 patients with carotid artery stenosis/occlusion undergoing cardiac surgery with cardiopulmonary bypass and assessed cerebral autoregulation by using transcranial Doppler sonography with $\mathrm{CO}_{2}$ stimulation. Increased risk of perioperative stroke was observed in patients with high-grade stenosis or occlusion and exhausted autoregulatory reserve, suggesting that assessment of CVR facilitates identification of patients with an excess perioperative stroke risk. $^{80}$

\section{Moyamoya Disease}

Moyamoya disease is a well-described entity characterized by progressive stenosis and occlusion of the supraclinoid ICA and its branches, affecting both the pediatric and adult population and frequently resulting in cerebral infarctions. ${ }^{81}$ Medical therapy for Moyamoya disease is ineffective; consequently, direct and indirect surgical revascularization has become the primary technique of treatment for these patients to reduce the incidence of ischemic sequelae. Many series have reported the efficacy of revascularization in this syndrome by using primarily direct superficial temporal artery (STA)-MCA bypass. $^{82-89}$

PET studies in Moyamoya disease have demonstrated re- 


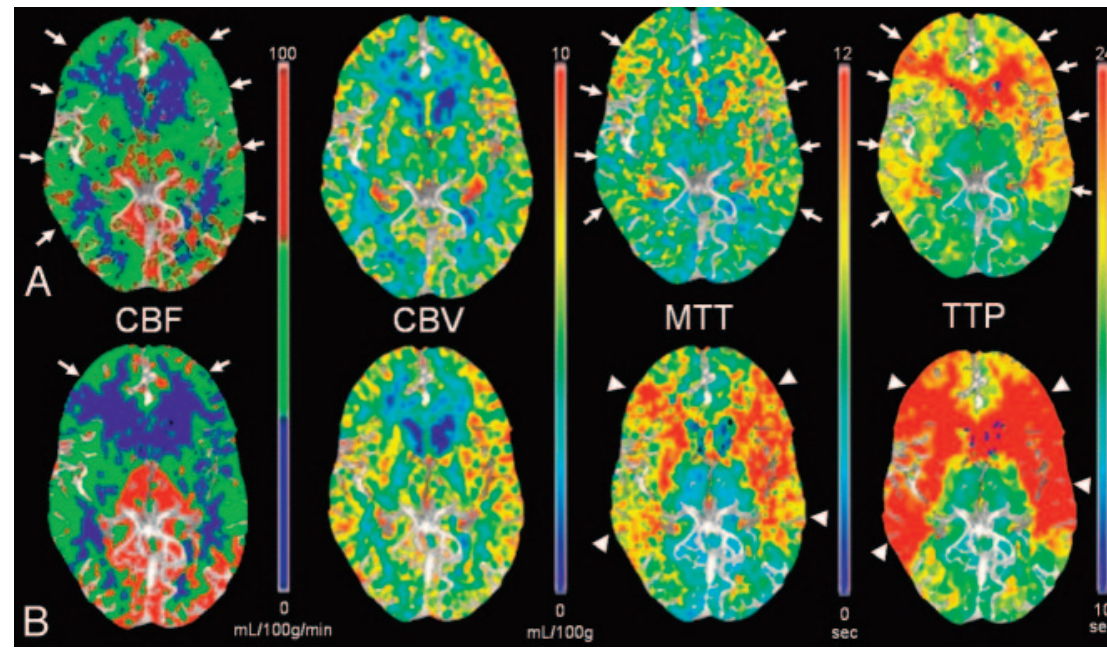

Fig 5. CT perfusion maps in a 51-year-old patient presenting with right-sided hemiparesis who was diagnosed with Moyamoya disease, demonstrating bilateral supraclinoid internal carotid occlusion. A, Baseline. B, After ACZ administration. The baseline pre-ACZ PCT $(A)$ demonstrates the typical pattern of Moyamoya disease with decreased CBF and increased MTT and TTP in the bilateral anterior and middle cerebral distributions (arrows). After ACZ challenge $(B)$, the $\mathrm{CBF}$ in the anterior circulation decreases consistent with steal phenomenon ( $B$, CBF, arrows). The CBF map demonstrates a normal expected increase in the PCA territories. There is further prolongation of the MTT and TTP in both ACA and MCA distributions (arrowheads, B), consistent with worsening of cerebral hemodynamics after ACZ, and type III physiology. The patient successfully underwent left-sided ECIC bypass surgery.

duced $\mathrm{CBF}$ and $\mathrm{CO}_{2}$ response and increased $\mathrm{CBV}$, MTT, and OEF. ${ }^{90} \mathrm{CBF}$ is significantly lower in patients with Moyamoya disease than in healthy subjects of the same age. Also the CBF has a dominant posterior distribution in contrast to the anterior distribution observed in healthy control subjects (Fig 5). ${ }^{91}$

CVR testing with ACZ challenge is useful in Moyamoya disease. CVR in the anterior cerebral and middle cerebral territories is significantly lower than that in the posterior cerebral territory and the central region around the basal ganglia. ${ }^{92}$ Of multiple hemodynamic parameters measured by ACZ challenge PCT in adult Moyamoya disease, percentage change in CBF correlated most significantly with the angiographic stage of the disease. ${ }^{93}$ Another study correlated ACZchallenged PCT with SPECT in patients with Moyamoya disease and showed that baseline PCT parameters, including CBV and MTT, correlated weakly with the CVR obtained with SPECT. ${ }^{33}$ The study demonstrated that percentage change of CBF correlated well with quantitative SPECT CVR measurements. ${ }^{33}$

\section{Pre- and Postoperative Evaluation of Extracranial- Intracranial Bypass for Flow Augmentation}

Cerebral revascularization by using extracranial-intracranial (ECIC) bypass is a treatment option in the setting of major cerebral artery occlusive disease. A large ECIC bypass study was initiated to determine whether anastomosis of the STA to the MCA could reduce ischemic stroke and stroke-related death among patients with symptomatic surgically inaccessible (to carotid endarterectomy [CEA]) atherosclerotic stenosis or occlusion of the ICA or MCA. ${ }^{94}$ Although this study failed to show the efficacy of bypass over medical management for anterior circulation occlusive disease, it preceded effective noninvasive tools for $\mathrm{CBF}$ testing. With greater understanding of the importance of assessing cerebral hemodynamics in patients with CVD, interest in revascularization has re-emerged.

In recent years, the use of ECIC bypass for anterior circulation ischemia in selected patients has been reported in several studies. ${ }^{95-97}$ Several case series have demonstrated benefit from ECIC bypass if the patient population is carefully defined. In a study by Mendelowitsch et al, ${ }^{98} 85 \%$ of the patients had no further cerebrovascular events after surgery in the average follow-up period of 44 months, and only 11\% experi- enced another cerebrovascular event. Following ECIC bypass, most (95.4\%) patients experience cessation of their ischemic events and stabilization of pre-existing neurologic dysfunction. ${ }^{99}$ To assess the efficacy of ECIC bypass in this group more definitively, a randomized trial, the Carotid Occlusion Surgery Study, is underway in North America. ${ }^{100}$ This study is funded by the National Institutes of Health, which stratifies patients as candidates for surgery only if they manifest increased OEF on PET.

Hemodynamic assessment, including CVR testing, represents an important assessment tool after ECIC bypass surgery. After ECIC bypass, several studies have shown that there can be full or partial reversal of impaired CVR (Fig 6). ${ }^{21,101,102}$ One study using ${ }^{133} \mathrm{Xe}$ SPECT in 28 patients who underwent ECIC bypass showed significant improvement of CVR after surgery while the resting CBF was essentially unchanged. ${ }^{103}$ Schaller ${ }^{104}$ concluded that the hemodynamic parameters observed in patients who experience improved neurologic function or diminished stroke risk profile after ECIC-bypass surgery contain both significantly elevated OEF and CBF/CBV.

Although the role of cerebral revascularization in patients with major cerebral artery occlusive diseases remains controversial, there is growing evidence that symptomatic patients with a documented hemodynamic source of their symptoms are very good candidates for undergoing STA-MCA bypass.

\section{Carotid Balloon Occlusion}

Balloon test occlusion of the ICA is performed routinely to assess the collateral circulation before surgical or endovascular procedures that may involve sacrificing or prolonged occlusion of the ICA. Patients who develop any change in the neurologic status during balloon occlusion are thought to demonstrate poor autoregulatory potential. Up to $10 \%$ of patients in whom the test is clinically successful may still have diminished CBF in the ipsilateral hemisphere. ${ }^{105,106}$

Perfusion imaging, pharmacologically induced hypotension, and stump pressure measurements are various methods used for evaluation during the balloon test occlusion. ${ }^{28}$ The feasibility of the ACZ challenge test during carotid balloon occlusion has been shown in a few studies. ${ }^{105,108}$ Using ACZ challenge and perfusion CT in a study of 8 patients, Jain et $\mathrm{al}^{107}$ suggested that patients with symmetric CBF and normal vaso- 


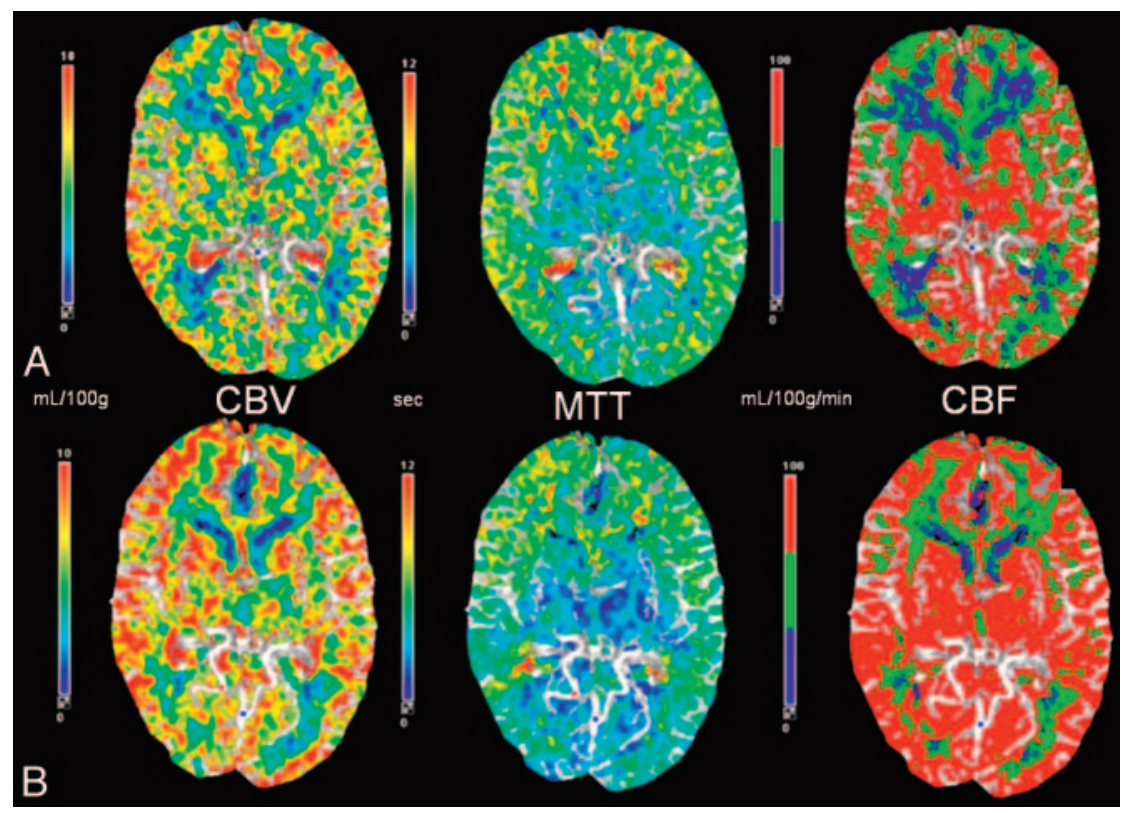

Fig 6. CT perfusion flow maps in a 56-year-old patient presenting with multiple transient ischemic episodes and diagnosed with Moyamoya disease with bilateral carotid occlusion on digital subtraction angiography before $(A)$ and 12 months after $(B)$ bilateral ECIC bypass surgery. The preoperative baseline maps $(A)$ show a typical pattern of Moyamoya disease with decreased CBF and increased MTT in the anterior circulation. After bilateral ECIC bypass ISTA-MCA, $B)$, there is an increase in the CBF in the ACA and MCA territories with minimal decrease in the MTT. The improvement is more pronounced in the MCA territory because of the proximity of the graft. Quantitatively, there is improvement in the CVR in these distributions. After bypass, the patient's ischemic symptoms resolved.

dilatory capacity would do well after permanent carotid occlusion and that patients with asymmetric CBF and abnormal response to the ACZ challenge test may require a revascularization procedure to protect them from future ischemic sequelae.

\section{Hyperperfusion Syndrome}

Cerebral hyperperfusion syndrome is an uncommon but serious complication of carotid revascularization, including CEA and carotid stent placement. Hyperperfusion syndrome (associated with increased CBF compared with preoperative values) results in headache, focal seizure activity, cerebral edema, and intracerebral hemorrhage and is associated with significant mortality and morbidity. ${ }^{29}$

Komoribayashi et al $^{109}$ reported hyperperfusion immediately after CEA in $56 \%$ of patients with reduced preoperative CVR. Another study measured concentrations of malondialdehyde-modified low-attenuation lipoprotein (MDA-LDL), a biochemical marker of oxidative damage, in serum samples and CVR measurements in 90 patients undergoing CEA. ${ }^{110}$ This study suggested that reduced preoperative CVR $(<20 \%)$ and increased MDA-LDL correlate with the development of cerebral hyperperfusion after CEA. ${ }^{110}$ In a more recent study, measurements of preoperative CBV by perfusion-weighted MR imaging helped to identify patients at risk for cerebral hyperperfusion after CEA. ${ }^{111}$ Other studies have also shown that preoperative measurement of reduced CVR $(<10 \% \mathrm{CBF}$ response to ACZ) results in the timely and reliable identification of patients at risk for hyperperfusion syndrome. ${ }^{112,113}$ In these patients, careful monitoring and control of blood pressure should be initiated even intraoperatively. ${ }^{112}$

\section{Conclusions}

In patients with chronic steno-occlusive disease, it is important to assess the capacity of the cerebral circulation to adjust to superimposed hemodynamic changes. Current research suggests that compromised CVR is an important risk factor of future ischemic sequelae. Administration of a vasodilator such as ACZ can assess cerebral reserve by observing cerebrovascular reactivity to hemodynamic stress. The ACZ challenge test is a useful clinical tool and can be used to optimize the treatment strategies for patients with chronic cerebral ischemic disease.

\section{Acknowledgment}

We thank Rhonda Strunk for technical assistance.

\section{References}

1. Kuroda, $\mathrm{S}$, Kamiyama $\mathrm{H}$, Abe $\mathrm{H}$, et al. Acetazolamide test in detecting reduced cerebral perfusion reserve and predicting long-term prognosis in patients with internal carotid artery occlusion. Neurosurgery 1993;32:912-19

2. Kuroda S, Houkin K, Kamiyama H, et al. Long-term prognosis of medically treated patients with internal carotid or middle cerebral artery occlusion can acetazolamide test predict it? Stroke 2001;32:2110-16

3. Kleiser B, Widder B. Course of carotid artery occlusions with impaired cerebrovascular reactivity. Stroke 1992;23:171-74

4. Vernieri F, Pasqualetti P, Passarelli F, et al. Outcome of carotid artery occlusion is predicted by cerebrovascular reactivity. Stroke 1999;30:593-98

5. Ogasawara K, Ogawa A, Terasaki K. Use of cerebrovascular reactivity in patients with symptomatic major cerebral artery occlusion to predict 5-year outcome: comparison of xenon-133 and iodine-123-IMP single-photon emission computed tomography. J Cereb Blood Flow Metab 2002;22:1142-48

6. Derdeyn CP, Grubb RL Jr, Powers WJ. Cerebral hemodynamic impairment methods of measurement and association with stroke risk. Neurology 1999;53:251-59

7. Derdeyn CP. Cerebral hemodynamics in carotid occlusive disease. AJNR Am J Neuroradiol 2003;24:1497-99

8. Derdeyn CP, Grubb RL Jr, Powers WJ. Hemodynamic and metabolic effects of middle cerebral artery stenosis and occlusion. AJNR Am J Neuroradiol 1998;19:1463-69

9. Derdeyn CP, Videen TO, Yundt KD, et al. Variability of cerebral blood volume and oxygen extraction: stages of cerebral hemodynamic impairment revisited. Brain 2002;125:595-607

10. Powers WJ. Cerebral hemodynamics in ischemic cerebrovascular disease. Ann Neurol 1991;29:231-40

11. Powers WJ, Press GA, Grubb RL, et al. The effect of hemodynamically significant carotid artery disease on the hemodynamic status of the cerebral circulation. Ann Intern Med 1987;106:27-34

12. Dirnagl U, Pulsinelli W. Autoregulation of cerebral blood flow in experimental focal brain ischemia. J Cereb Blood Flow Metab 1990;10:327-36

13. Kety SS, King BD, Horvath SM, et al. The effects of an acute reduction in blood pressure by means of differential spinal sympathetic block on the cerebral circulation of hypertensive patients. J Clin Invest 1950;29:402-07

14. Baron JC, Bousser MG, Rey A, et al. Reversal of focal "misery perfusion syndrome" by extra-intracranial bypass in hemodynamic cerebral ischemia: a case study with 0-15 positron emission tomography. Stroke 1981;12:454-59 
15. Schumann P, Touzani O, Young AR, et al. Evaluation of the ratio of cerebral blood flow to cerebral blood volume as an index of local cerebral perfusion pressure. Brain 1998;121:1369-79

16. McHenry LC Jr, Fazekas JF, Sullivan JF. Cerebral hemodynamics of syncope. Am J Med Sci 1961;80:173-78

17. Grubb RL Jr, Raichle ME, Phelps ME, et al. Effects of increased intracranial pressure on cerebral blood volume, blood flow, and oxygen utilization in monkeys. J Neurosurg 1975;43:385-98

18. Baron JC. Perfusion thresholds in human ischemia: historical perspective and therapeutic applications. Cerebrovasc Dis 2001;11:2-8

19. Rogg J, Rutigliano $\mathrm{M}$, Yonas $\mathrm{H}$, et al. The acetazolamide challenge: imaging techniques designed to evaluate cerebral blood flow reserve. AJR American J Roentegenol 1989;53:605-12

20. Yonas H, Pindzola RR. Physiological determination of cerebrovascular reserves and its use in clinical management. Cerebrovasc Brain Metab Rev 1994;6:325-40

21. Vorstrup S, Brun B, Lassen NA. Evaluation of cerebral vasodilatory capacity by acetazolamide test before EC-IC bypass surgery in patients with occlusion of the internal carotid artery. Stroke 1986;17:1291-98

22. Lassen NA, Palvolgyi R. Cerebral steal during hypercapnia and the inverse reaction during hypocapnia observed with the 133 xenon technique in man. Scand J Chin Lab Invest Suppl 1968;102:XIII:D

23. Sullivan HG, Kingsbury TB, Morgan ME, et al. The rCBF response to Diamox in normal subjects and cerebrovascular disease patients. J Neurosurg 1987;67:525-34

24. Burt RW, Witt RM, Cikrit DF, et al. Carotid artery disease: evaluation with acetazolamide-enhanced Tc-99m HMPAO SPECT. Radiology 1992;182: 461-66

25. Komiyama M, Nishikawa M, Yasui $T$, et al. Reversible pontine ischemia caused by acetazolamide challenge. AJNR Am J Neuroradiol 1997;18:1782-84

26. Piepgras A, Schmiedek P, Leinsinger G, et al. A simple test to assess cerebrovascular reserve capacity using transcranial Doppler sonography and acetazolamide. Stroke 1990;21:1306-11

27. Epocrates online. Available at: http://www.rxlist.com/acetazolamideinjection-drug.htm. Accessed December 29, 2008

28. Yonas H, Darby JM, Marks EC, et al. CBF measured by xe-CT: approach to analysis and normal values. J Cereb Blood Flow Metab 1991;11:716-25

29. Eskey CJ, Sanelli PC. Perfusion imaging of cerebrovascular reserve. Neuroimag Clin N Am 2005;15:367-81

30. Yonas H, Pindzola RR, Meltzer CC, et al. Qualitative versus quantitative assessment of cerebrovascular reserves. Neurosurgery 1998;42:1005-12

31. Latchaw RE, Yonas H, Pentheny SL, et al. Adverse reactions to xenon-enhanced CT cerebral blood flow determination. Radiology 1987;163:251-54

32. Chen A, Shyr M-H, Chen T-Y, et al. Dynamic CT perfusion imaging with acetazolamide challenge for evaluation of patients with unilateral cerebrovascular steno-occlusive disease. AJNR Am J Neuroradiol 2006;27:1876-81

33. Rim NJ, Kim HS, Shin YS, et al. Which CT perfusion parameter best reflects cerebrovascular reserve? Correlation of acetazolamide-challenged CT perfusion with single-photon emission CT in Moyamoya patients. AJNR Am J Neuroradiol 2008;29:1658-63

34. Eastwood JD, Alexander MJ, Petrella JR, et al. Dynamic CT perfusion imaging with acetazolamide challenge for the preprocedural evaluation of a patient with symptomatic middle cerebral artery occlusive disease. AJNR Am J Neuroradiol 2002;23:285-87

35. Furukawa M, Kashiwagi S, Matsunaga N, et al. Evaluation of cerebral perfusion parameters measured by perfusion CT in chronic cerebral ischemia: comparison with xenon CT. J Comput Assist Tomogr 2002;26:272-78

36. Gillard JH, Minhas PS, Hayball MP, et al. Assessment of quantitative computed tomographic cerebral perfusion imaging with $\mathrm{H} 215 \mathrm{O}$ positron emission tomography. Neurol Res 2000;22:457-64

37. Bisdas S, Nemetiz O, Berding G, et al. Correlative assessment of cerebral blood flow obtained with perfusion CT and positron emission tomography in symptomatic stenotic carotid disease. Eur Radiol 2006;16:2220-28

38. Kudo K, Terae S, Katoh C, et al. Quantitative cerebral blood flow measurement with dynamic perfusion CT using the vascular-pixel elimination method: comparison with $\mathrm{H} 2(15) \mathrm{O}$ positron emission tomography. AJNR Am J Neuroradiol 2003;24:419-26

39. Kealey SM, Loving VA, Delong DM, et al. User-defined vascular input function curves: influence on mean perfusion parameter values and signal-tonoise ratio. Radiology 2004;231:587-93

40. Sanelli PC, Nicola G, Tsiouris AJ, et al. Reproducibility of postprocessing of quantitative CT perfusion maps. AJR Am J Roentgenol 2007;188:213-18

41. Waaijer A,Van der Schaaf IC,Velthuis BK, et al. Reproducibility of quantitative CT brain perfusion measurements in patients with symptomatic unilateral carotid artery stenosis. AJNR Am J Neuroradiol 2007;28:927-32

42. Navabi DG, Cenic A, Craen RA, et al. CT assessment of cerebral perfusion: experimental validation and initial clinical experience. Radiology 1999;213: $141-49$

43. Kamath A, Smith WS, Powers WJ, et al. Perfusion CT compared to $\mathbf{H}(2)$ (15) O/O (15)O PET in patients with chronic cervical carotid artery occlusion. Neuroradiology 2008;50:745-51. Epub 2008 May 29
44. Sakamoto S, Ohba S, Shibukawa M, et al. CT perfusion imaging for childhood Moyamoya disease before and after surgical revascularization. Acta Neurochir (Wien) 2006;148:77-81. Epub 2005 Sep 26

45. Lin W, Celik A, Derdeyn C, et al. Quantitative measurements of cerebra blood flow in patients with unilateral carotid artery occlusion: a PET and MR study. J Magn Reson Imaging 2001;14:659-67

46. Mukherjee P, Kang HC, Videen TO, et al. Measurement of cerebral blood flow in chronic carotid occlusive disease: comparison of dynamic susceptibility contrast perfusion MR imaging with positron emission tomography. AJNR Am J Neuroradiol 2003;24:862-71

47. Berthezene $\mathrm{Y}$, Nighoghossian $\mathrm{N}$, Meyer R, et al. Can cerebrovascular reactivity be assessed by dynamic susceptibility contrast-enhanced MRI? Neuroradiol ogy 1998;40:1-5

48. Guckel FJ, Brix G, Schmiedek P, et al. Cerebrovascular reserve capacity in patients with occlusive cerebrovascular disease: assessment with dynamic susceptibility contrast-enhanced MR imaging and the acetazolamide stimulation test. Radiology 1996;201:405-12

49. Schreiber WG, Guckel F, Stritzke P, et al. Cerebral blood flow and cerebrovascular reserve capacity: estimation by dynamic magnetic resonance imaging. J Cereb Blood Flow Metab 1998;18:1143-56

50. Yen YF, Field AS, Martin EM, et al. Test-retest reproducibility of quantitative CBF measurements using FAIR perfusion MRI and acetazolamide challenge. Magn Reson Med 2002;47:921-28

51. Detre JA, Samuels OB, Alsop DC, et al. Noninvasive magnetic resonance imaging evaluation of cerebral blood flow with acetazolamide challenge in patients with cerebrovascular stenosis. J Magn Reson Imaging 1999;10:870-75

52. Ma J, Mehrkens JH, Holtmannspoetter M, et al. Perfusion MRI before and after acetazolamide administration for assessment of cerebrovascular reserve capacity in patients with symptomatic internal carotid artery (ICA) occlusion: comparison with 99mTc-ECD SPECT. Neuroradiology 2007;49: 317-26. Epub 2007 Jan 3

53. Grandin CB, Bol A, Smith AM, et al. Absolute CBF and CBV measurements by MRI bolus tracking before and after acetazolamide challenge: repeatability and comparison with PET in humans. Neuroimage 2005;26:525-35

54. Wirestam R, Andersson L, Ostergaard L, et al. Assessment of regional cerebral blood flow by dynamic susceptibility contrast MRI using different deconvolution techniques. Magn Reson Med 2000;43:691-70

55. Rempp KA, Brix G, Wenz F, et al. Quantification of regional cerebral blood flow and volume with dynamic susceptibility contrast-enhanced MR imaging. Radiology 1994;193:637-41

56. Vonken EJ, van Osch MJ, Bakker CJ, et al. Measurement of cerebral perfusion with dual-echo multi-slice quantitative dynamic susceptibility contrast MRI. J Magn Reson Imaging 1999;10:109-17

57. Arbab AS, Aoki S, Toyama K, et al. Quantitative measurement of regional cerebral blood flow with flow-sensitive alternating inversion recovery imaging: comparison with [Iodine 123]-iodoamphetamin single photon emission CT. AJNR Am J Neuroradiol 2002;23:381-88

58. Deibler AR, Pollock JM, Kraft RA, et al. Arterial spin-labeling in routine clinical practice. Part 1. Technique and artifacts. AJNR Am J Neuroradio 2008;29:1228-34

59. Deibler AR, Pollock JM, Kraft RA, et al. Arterial spin-labeling in routine clinical practice. Part 2. Hypoperfusion patterns. AJNR Am J Neuroradiol 2008;29:1235-41

60. Gibbs JM, Wise RJ, Leenders KI, et al. Evaluation of cerebral perfusion reserve in patients with carotid-artery occlusion. Lancet 1984;1:310-14

61. Yamauchi H, Fukuyama H, Nagahama Y, et al. Significance of increased oxy gen extraction fraction in five-year prognosis of major cerebral arterial occlusive diseases. J Nucl Med 1999;40:1992-98

62. Grubb RL Jr, Derdeyn CP, Fritsch SM, et al. Importance of hemodynamic factors in the prognosis of symptomatic carotid occlusion. JAMA 1998;280:1055-60

63. Kuroda S, Shiga T, Houkin K, et al. Cerebral oxygen metabolism and neuronal integrity in patients with impaired vasoreactivity attributable to occlusive carotid artery disease. Stroke 2006;37:393-98. Epub 2005 Dec 29

64. Nemoto EM, Yonas $\mathrm{H}$, Kuwabara $\mathrm{H}$, et al. Identification of hemodynamic compromise by cerebrovascular reserve and oxygen extraction fraction in occlusive vascular disease. J Cereb Blood Flow Metab 2004;24:1081-89

65. Hokari M, Kuroda S, Shiga T, et al. Impact of oxygen extraction fraction on long-term prognosis in patients with reduced blood flow and vasoreactivity because of occlusive carotid artery disease. Surg Neurol 2008 May 29. [Epub ahead of print]

66. Derdeyn CP, Videen TO, Fritsch SM, et al. Compensatory mechanisms for chronic cerebral hypoperfusion in patients with carotid occlusion. Stroke 1999;30:1019-24

67. Powers WJ, Martin WR, Herscovitch P, et al. Extracranial-intracranial bypass surgery: hemodynamic and metabolic effects. Neurology 1984;34:168-74

68. Ogasawara K, Ito $\mathrm{H}$, Sasoh M, et al. Quantitative measurement of regional cerebrovascular reactivity to acetazolamide using 123I-N-isopropyl-p-iodoamphetamine autoradiography with SPECT: validation study using H2 150 with PET. J Nucl Med 2003;44:520-25

69. Okazawa $\mathrm{H}$, Yamauchi $\mathrm{H}$, Sugimoto $\mathrm{K}$, et al. Differences in vasodilatory ca- 
pacity and changes in cerebral blood flow induced by acetazolamide in patients with cerebrovascular disease. J Nucl Med 2003;44:1371-78

70. Hashikawa K, Matsumoto M, Moriwaki H, et al. Split dose iodine-123-IMP SPECT: sequential quantitative regional cerebral blood flow change with pharmacological intervention. J Nucl Med 1994;35:1226-33

71. Hattori N, Yonekura Y, Tanaka F, et al. One day protocol for cerebral perfusion reserve with acetazolamide. J Nucl Med 1996;37:2057-61

72. Sugawara $Y$, Kikuchi $T$, Ueda $T$, et al. Usefulness of brain SPECT to evaluate brain tolerance and hemodynamic changes during temporary balloon occlusion test and after permanent carotid occlusion. J Nucl Med 2002;43:1616-23

73. Hiroaki $\mathrm{H}$, Takashi $\mathrm{O}$, Seishi J, et al. Cerebral blood flow study in patients with Moyamoya disease evaluated by IMP SPECT. J Nucl Med 1994;35:44-50

74. Lee HY, Paeng JC, Lee DS, et al. Efficacy assessment of cerebral arterial bypass surgery using statistical parametric mapping and probabilistic brain atlas on basal/acetazolamide brain perfusion SPECT. J Nucl Med 2004;45:202-06

75. Webster MW, Makaroun MS, Steed DL, et al. Compromised cerebral blood flow reactivity is a predictor of stroke in patients with symptomatic carotid artery occlusive disease. J Vasc Surg 1995;21:1-13

76. Derdeyn CP, Carpenter DA, Videen TO, et al. Patterns of infarction in hemodynamic failure. Cerebrovasc Dis 2007;24:11-19

77. Derdeyn CP. Mechanisms of ischemic stroke secondary to large artery atherosclerotic disease. Neuroimaging Clin N Am 2007;17:303-11

78. Yonas H, Smith HA, Durham SR, et al. Increase stroke risk predicted by compromised cerebral blood flow reactivity. J Neurosurg 1993;79:483-89

79. Silvestrini M, Vernieri F, Pasqualetti P, et al. Impaired cerebral vasoreactivity and risk of stroke in patients with asymptomatic carotid artery stenosis. JAMA 2000;283:2122-27

80. Schoof J, Lubahn W, Baeumer M, et al. Impaired cerebral autoregulation distal to carotid stenosis/occlusion is associated with increased risk of stroke at cardiac surgery with cardiopulmonary bypass. J Thorac Cardiovasc Surg 2007;134:690-96

81. Suzuki J, Takaku A. Cerebral vascular "Moyamoya disease": a disease showing abnormal net-like vessels in base of brain. Arch Neurol 1969;20:288-99

82. Mesiwala AH, Sviri G, Fatemi N, et al. Long-term outcome of superficial temporal artery-middle cerebral artery bypass for patients with Moyamoya disease in the US. Neurosurg Focus 2008;24:E15

83. Imaizumi T, Hayashi K, Saito K, et al. Long-term outcomes of pediatric Moyamoya disease monitored to adulthood. Pediatr Neurol 1998;18:321-25

84. Karasawa J, Touho $\mathrm{H}$, Ohnishi $\mathrm{H}$, et al. Long-term follow-up study after extracranial-intracranial bypass surgery for anterior circulation ischemia in childhood Moyamoya disease. J Neurosurg 1992;77:84-89

85. Isono M, Ishii K, Kamida T, et al. Long-term outcomes of pediatric Moyamoya disease treated by encephalo-duro-arterio-synangiosis. Pediatr Neurosurg 2002;36:14-21

86. Karasawa J, Kikuchi H, Furuse S, et al. Treatment of Moyamoya disease with STA-MCA anastomosis. J Neurosurg 1978;49:679-88

87. Houkin K, Kuroda S, Nakayama N. Cerebral revascularization for Moyamoya disease in children. Neurosurg Clin North Am 2001;12:575-84, ix

88. Srinivasan J, Britz GW, Newell DW. Cerebral revascularization for Moyamoya disease in adults. Neurosurg Clin North Am 2001;12:585-94, ix

89. Ishikawa T, Houkin $\mathrm{K}$, Kamiyama $\mathrm{H}$, et al. Effects of surgical revascularization on outcome of patients with pediatric Moyamoya disease. Stroke 1997;28:1170-73

90. Kuwubara Y, Ichiya Y, Otsuka M, et al. Cerebral hemodynamic change in the child and the adult with Moyamoya disease. Stroke 1990;21:272-77

91. Ogawa A, Yoshimoto T, Suzuki J, et al. Cerebral blood flow in Moyamoya disease. Part 1. Correlation with age and regional distribution. Acta Neurochir (Wien) 1990;105:30-34

92. Seung-Koo L, Dong K, Eun-Kee J, et al. Postoperative evaluation of Moyamoya disease with perfusion-weighted MR imaging: initial experience. $A J N R$ Am J Neuroradiol 2003;24:741-47

93. Kang KH, Kim HS, Kim SY. Quantitative cerebrovascular reserve measured by acetazolamide-challenged dynamic CT perfusion in ischemic adult Moyamoya disease: initial experience with angiographic correlation. AJNR Am J Neuroradiol 2008;29:1487-93

94. Failure of extracranial-intracranial arterial bypass to reduce the risk of ischemic stroke: results of an international randomized trial-The EC/IC Bypass Study Group. N Engl J Med 1985:313:1191-200
95. Nussbaum ES, Erickson DL. Extracranial-intracranial bypass for ischemic cerebrovascular disease refractory to maximal medical therapy. Neurosurgery 2000;46:37-42

96. Klijn CJ, Kappelle LJ,van der Zwan A, et al. Excimer laser-assisted high-flow extracranial/intracranial bypass in patients with symptomatic carotid occlusion at high risk of recurrent cerebral ischemia: safety and long-term outcome. Stroke 2002;33:2451-58

97. Amin-Hanjani S, Butler WE, Ogilvy CS, et al. Extracranial bypass in the treatment of occlusive cerebrovascular disease and intracranial aneurysms in United States between 1992 and 2001: a population-based study. J Neurosurg 2005; 103:794-804

98. Mendelowitsch A, Taussky P, Rem JA, et al. Clinical outcome of standard extracranial-intracranial bypass surgery in patients with symptomatic ath erosclerotic occlusion of the internal carotid artery. Acta Neurochir (Wien) 2004;146:95-101

99. Tummala RP, Chu RM, Nussbaum ES. Extracranial-intracranial bypass for symptomatic occlusive cerebrovascular disease not amenable to carotid endarterectomy. Neurosurg Focus 2003;14:e8

100. Adams HP Jr, Powers WJ, Grubb RL Jr, et al. Preview of a new trial of extracranial-to-intracranial arterial anastomosis: the carotid occlusion surgery study. Neurosurg Clin North Am 2001;12:613-24, ix-x

101. Anderson DE, McLane MP, Reichman OH, et al. Improved cerebral blood flow and $\mathrm{CO} 2$ reactivity after microvascular anastomosis in patients at high risk for recurrent stroke. Neurosurgery 1992;31:26-33

102. Yamashita T, Kashiwagi S, Nakano S, et al. The effect of EC-IC bypass surgery on resting cerebral blood flow and cerebrovascular reserve capacity studied with stable xe-CT and acetazolamide test. Neuroradiology 1991;33:217-22

103. Schmiedek P, Piepgras A, Leinsinger G, et al. Improvement of cerebrovascular reserve capacity by EC-IC arterial bypass surgery in patients with ICA occlusion and hemodynamic cerebral ischemia. J Neurosurg 1994;81:236-44

104. Schaller B. Extracranial-intracranial bypass surgery to reduce the risk of haemodynamic stroke in cerebroocclusive atherosclerotic disease of the anterior cerebral circulation: a systematic review. Neurol Neurochir Pol 2007;41:457-71

105. Mathis JM, Barr JD, Jungreis CA, et al. Temporary balloon test occlusion of the internal carotid artery: experience in $\mathbf{5 0 0}$ cases. AJNR Am J Neuroradio 1995; $16: 749-54$

106. Linskey ME, Jungreis CA, Yonas $\mathrm{H}$, et al. Stroke risk after abrupt internal carotid artery sacrifice: accuracy of preoperative assessment with balloon test occlusion and stable xenon-enhanced CT. AJNR Am J Neuroradio 1994; $15: 829-43$

107. Jain R, Hoeffner EG, Deveikis JP, et al. Carotid perfusion CT with balloon occlusion and acetazolamide challenge test: feasibility. Radiology 2004;231:906-13

108. Okudaira Y, Arai H, Sato K. Cerebral blood flow alteration by acetazolamide during carotid balloon occlusion: parameters reflecting cerebral perfusion pressure in the acetazolamide test. Stroke 1996;27:617-21

109. Komoribayashi N, Ogasawara K, Kobayashi M, et al. Cerebral hyperperfusion after carotid endarterectomy is associated with preoperative hemodynamic impairment and intraoperative cerebral ischemia. J Cereb Blood Flow Metab 2006;26:878-84. Epub 2005 Nov 9

110. Suga Y, Ogasawara K, Saito H, et al. Preoperative cerebral hemodynamic impairment and reactive oxygen species produced during carotid endarterectomy correlate with development of postoperative cerebral hyperperfusion. Stroke 2007;38:2712-17

111. Fukuda T, Ogasawara K, Kobayashi M, et al. Prediction of cerebral hyperperfusion after carotid endarterectomy using cerebral blood volume measured by perfusion-weighted MR imaging compared with single-photon emission CT. AJNR Am J Neuroradiol 2007;28:737-42

112. Hosoda K, Kawaguchi T, Shibata Y, et al. Cerebral vasoreactivity and interna carotid artery flow help to identify patients at risk for hyperperfusion after carotid endarterectomy. Stroke 2001;32:1567-73

113. Ogasawara K, Yukawa H, Kobayashi M, et al. Prediction and monitoring of cerebral hyperperfusion after carotid endarterectomy by using single-photon emission computerized tomography scanning. J Neurosurg 2003;99: $504-10$ 